\title{
Carboxy-terminal elements of c-Myb negatively regulate transcriptional activation in cis and in trans
}

\author{
John W. Dubendorff, Linda J. Whittaker, Jason T. Eltman, and Joseph S. Lipsick \\ Department of Microbiology, School of Medicine, State University of New York at Stony Brook, \\ Stony Brook, New York 11794-8621 USA
}

\begin{abstract}
The c-Myb protein plays a key role in normal hematopoiesis, and truncation results in its activation to a transforming protein. Truncation of the c-Myb carboxyl terminus also greatly increases its transcriptional activating activity. The role of specific carboxy-terminal domains in negative regulation was investigated using Myb and Myb fusions with GAL4, LexA, or VP16. Negative regulatory activity of the carboxyl terminus in cis resides in at least two regions. A sequence in one of these regions can also inhibit transcriptional activation by Myb, Myb-VP16, or LexA-Myb proteins in trans. Regulation in trans, or suppression, is independent of c-Myb DNA binding and, therefore, likely involves protein-protein interaction. Suppression does not require the presence of a predicted heptad leucine repeat structure on either molecule. The target of suppression is a sequence that contains part of the minimal Myb transcriptional activation domain. This sequence can confer suppressibility on fusion proteins containing heterologous DNA-binding or transcriptional activation domains.
\end{abstract}

[Key Words: Negative regulation; transcription; suppression; c-Myb; oncogene]

Received June 22, 1992; revised version accepted October 14, 1992.

The myb oncogene has been implicated in the control of cell proliferation and differentiation during hematopoiesis (for review, see Lüscher and Eisenman 1990; ShenOng 1990). Viral transduction of the cellular progenitor c-myb into the avian myeloblastosis virus (AMV) resulted in truncation of 71 amino acids from the amino terminus and 199 amino acids from the carboxyl terminus of the protein (Gerondakis and Bishop 1986; Rosson and Reddy 1986). The v-myb gene of AMV also suffered multiple specific amino acid substitutions during transduction. Single or double truncation of the wild-type c-Myb sequence was shown to be sufficient for activation of transforming potential (Grasser et al. 1991), but introduction of the v-Myb amino acid changes was not required (Stober-Grasser and Lipsick 1988). Various amino acid substitutions in $\mathrm{v}-\mathrm{Myb}$ and single versus double truncation of c-Myb can influence the type of blood precursor cell that is transformed. AMV transforms precursors of the monocyte/macrophage lineage, whereas viruses expressing single or double truncation of c-Myb transform cells at different stages along the granulocyte pathway (Grasser et al. 1991). Disruptions of the c-myb locus by proviral insertion result in truncations similar to those found in transforming retrovinuses and give rise to a variety of hematopoietic tumors (Shen-Ong 1990). Mice that are homozygous for a c-myb disruption are severely anemic and die in utero due to defective fetal hematopoiesis (Mucenski et al. 1991). Treatment with antisense oligonucleotides directed at c-Myb can also inhibit hematopoiesis in vitro /Gewirtz and Calabretta 1988). These observations suggest that Myb plays a critical role in the development of a normal hematopoietic system.

Both v-Myb and c-Myb have been shown to function as transcriptional activators (Klempnauer et al. 1989; Ness et al. 1989; Sakura et al. 1989; Weston and Bishop 1989; Ibanez and Lipsick 1990). Genes encoding Myb-like proteins have been isolated from a wide range of species including organisms as diverse as the cellular slime mold Dictyostelium, yeast, Drosophila, and maize (StoberGrasser et al. 1992 and references therein). Avian, murine, and human forms of c-Myb are highly homologous nuclear proteins of nearly identical size (Klempnauer et al. 1983; Boyle et al. 1986). The c-Myb proteins of these higher vertebrates possess a highly conserved amino-terminal DNA-binding domain composed of three imperfect 50-amino-acid repeats, a central transcriptional activation domain, and a carboxy-terminal negative regulatory region (Sakura et al. 1989). Possession of at least two of the amino-terminal repeats has been shown to specify binding to the DNA sequence PyAAC/G/T)G (Biedenkapp et al. 1988; Howe et al. 1990; Oehler et al. 1990; Garcia et al. 1991). The high degree of amino acid sequence conservation in the DNA-binding domain of Myb proteins from widely divergent species suggests an important role for the DNA-binding function of Myb. 
Additional work suggests that association of Myb with other proteins may be critical to the transformation process. Several mutations in the DNA-binding domain of Myb-related proteins have been described that can bind DNA in vitro but that are defective for transcriptional activation and/or transformation in vivo (Lane et al. 1990; Goff et al. 1991; Grasser et al. 1992). Furthermore, when two of the amino acid changes present in the $\mathrm{v}-\mathrm{Myb}$ DNA-binding domain are individually back-mutated, the lineage of the transformed cells is altered (Introna et al. 1990). A heptad leucine repeat sequence located carboxy-terminal to the transcriptional activation domain in both v-Myb and c-Myb has recently been suggested to play a role in transactivation and transformation (Kanei-Ishii et al. 1992). These investigators hypothesize that binding of Myb to another protein through this putative leucine zipper is necessary for negative regulation of its activity.

Truncation of the carboxy-terminal region from $\mathrm{c}-\mathrm{Myb}$, in addition to activating its transforming potential, greatly increases the transcriptional activation activity of the protein (Sakura et al. 1989; Kalkbrenner et al. 1990). Although there seems to be some correlation between transactivating and transforming functions of v-Myb (Lane et al. 1990), not all transcriptionally active Myb proteins are competent for transformation. For example, a fusion of $\mathrm{v}$-Myb to the transcriptional activation domain of the herpes simplex virus protein VPl6 is a very strong activator (Ibanez and Lipsick 1990) but does not transform (U. Engelke and J. Lipsick, unpubl.). Furthermore, internal deletion of a region in the carboxyl terminus of c-Myb that is highly conserved between vertebrates and Drosophila also fails to activate transformation (Grasser et al. 1991). We therefore performed a comprehensive deletion analysis to map the functional domains in the carboxyl terminus involved in transcriptional regulation by c-Myb and to elucidate their mechanism of action. The negative regulatory region of $\mathrm{c}-\mathrm{Myb}$ is comprised of two domains, either one of which is sufficient in cis. One of these domains also inhibits transcriptional activation in trans (suppresses) through a specific Myb target sequence that can confer suppressibility on heterologous DNA-binding or activation domains. Our results show that the c-Myb carboxyl terminus contains functionally complex sequences capable of negatively regulating Myb transcriptional activation activity both in cis and in trans. We present possible models for these functions of the c-Myb carboxyl terminus.

\section{Results}

Identification of two negative regulatory regions in the carboxyl terminus of chicken $c-M y b$

Transcriptional activation studies using murine and human c-Myb have shown that deletions in the carboxyterminal region can greatly increase its transcriptional stimulation capacity (Sakura et al. 1989; Kalkbrenner et al. 1990). These studies placed the "negative regulatory domain" in two essentially nonoverlapping regions of the carboxyl terminus corresponding to amino acids 416-499 and 497-641 of chicken c-Myb. To test for the presence of a negative regulatory domain in the chicken homolog, we first tested deletions of c-Myb corresponding approximately to the truncations present in the $\mathrm{v}$-Myb protein, both individually and in combination. These deletions (d) remove either amino-terminal sequences (dCC), carboxy-terminal sequences (CCd), or both (dCd) from the full-length c-Myb protein, CCC (Fig. 1) (Grasser et al. 1991). Expression of the chloramphenicol acetyltransferase (CAT) gene driven by a tandem array of Myb-binding sites upstream of the E1b TATA sequence was assayed using transient transfections of viral vectors in QT6 quail fibroblasts (Fig. 1). Full-length c-Myb was essentially inactive. Amino-terminal truncation had little effect on transcription levels, whereas carboxy-terminal truncation consistently increased transcription. A control reporter plasmid lacking Myb-binding sites failed to give CAT activity above background. Essentially the same results were observed in HD-11 cells, a v-Myc-transformed macrophage cell line that does not express c-Myb (data not shown). Thus, the carboxyl terminus of chicken c-Myb contains sequences capable of negatively regulating its transcriptional activation capability.

To investigate whether negative regulation by the carboxyl terminus of chicken c-Myb required the presence of the highly conserved Myb DNA-binding domain, we constructed a fusion protein in which the amino-terminal DNA-binding region of chicken c-Myb was replaced

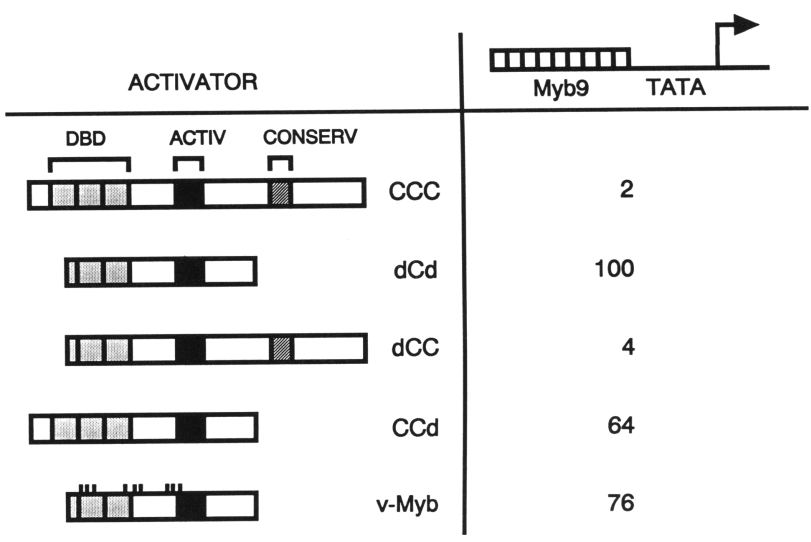

Figure 1. Transcriptional activation by $c-M y b$, truncated $\mathrm{c}-\mathrm{Myb}$, and $\mathrm{v}-\mathrm{Myb}$ proteins. The transcriptional activities of different Myb proteins are shown as a percent of the best activator, $\mathrm{dCd}$. Schematic diagrams of the proteins are shown at left, with the DNA-binding domain (stippled), transcriptional activation domain (black), and carboxy-terminal conserved region (hatched) indicated. The lines above the $\mathrm{v}$-Myb diagram indicate amino acid substitutions relative to $\mathrm{c}-\mathrm{Myb}$. Promoter elements directing CAT gene expression (nine Myb-binding sites and a minimal TATA sequence) are shown at the top. Reporter $(1 \mu \mathrm{g})$ and activator $(5 \mu \mathrm{g})$ plasmids were cotransfected into QT6 quail fibroblasts, and activities were determined as described in Materials and methods. In this experiment $100 \%$ activity represents $11,000 \mathrm{cpm}$. 
by the unrelated DNA-binding domain of the yeast transcriptional activator GAL4 (Kakidani and Ptashne 1988). Amino acids 1-147 of GAL4, which also contain a nuclear localization signal, were fused to amino acids 233641 of c-Myb at a site between the c-Myb DNA-binding and activation domains. This construct is similar to that used by Kalkbrenner et al. (1990), except that it contains additional GAL4 sequences necessary for efficient dimerization by GAL4, and will be referred to hereafter as GAL4-c-Myb (GAL4-CC). An additional construct was made that is truncated at C-Myb amino acid 428 near the position of $\mathrm{v}-\mathrm{Myb}$ carboxy-terminal truncation [deletion (d) 428-641 in Fig. 2; also called GAL4-Cd]. Transfection of these plasmids, along with a reporter plasmid having five GAL4-binding sites upstream of the E1b TATA sequence and CAT gene, demonstrated that negative regulation by carboxy-terminal sequences of chicken c-Myb also functions in the context of a heterologous DNA-binding domain. Transcriptional activation by the full-length GAL4-c-Myb fusion (GAL4-CC) was negligible; however, the truncation of the Myb sequence in d428-641 resulted in greatly increased levels of activation (Fig. 2). Transcriptional activation from a control reporter plasmid lacking GAL4 sites was negli- gible (data not shown). The GAL4 DNA-binding domain alone, designated GAL4(DBD) in Figure 2, did not activate. Similar results were obtained with BK3A cells, an avian leukosis virus-transformed B-cell line that expresses high levels of endogenous c-Myb (Lüscher et al. $1990 a_{\text {; }}$ data not shown).

Progressive truncation from the carboxyl terminus (Table 1) identified a region between amino acids 428 and 462 (MscI-SacI) that is necessary for strong negative regulatory function. Transcriptional activation by the fusion protein truncated to BgIII (amino acid 499) resulted in low levels of CAT activity (Fig. 2). Further truncation to the upstream SacI site (amino acid 463) resulted in only a slight increase in CAT activity. However, additional truncation to the MscI site (amino acid 428) significantly increased CAT expression (about sixfold). This protein exhibited the greatest activity even though it was considerably less abundant than the others as shown by immunoblotting of extracts from the same cells (Fig. 2). Each of the other constructs produced similar steadystate levels of fusion protein of the expected molecular weight. Therefore, differences in transcriptional activation were not the result of different protein stabilities.

Six small deletions of between 35 and 61 amino acids
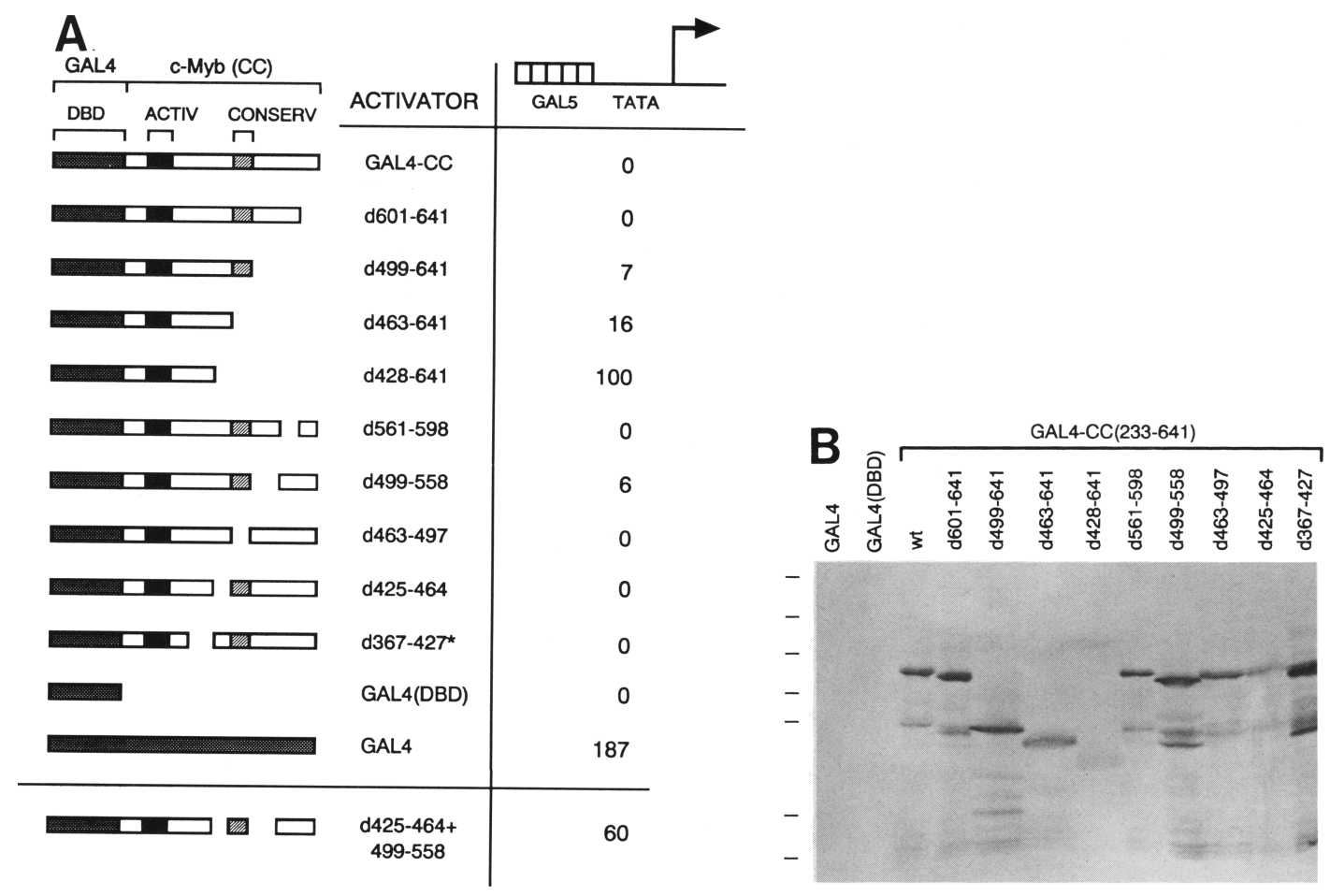

Figure 2. Negative regulation of GAL4-c-Myb by carboxy-terminal sequences in cis. $(A)$ The transcriptional activities of GAL4-cMyb and its deletion mutants are shown relative to the best activator, d428-641 (GAL4-Cd). The schematics showing GAL4 (crosshatched) and c-Myb sequences, and promoter elements that direct CAT expression are as in Fig. 1, except that five GAL4-binding sites replace the nine sites specific for Myb. The asterisk (*) indicates the deletion that removes the potential Myb leucine zipper structure. The double deletion $\mathrm{d} 425-464+499-558$ was tested in a separate experiment along with d428-641 to which its activity was also normalized. Transfections of reporter $(1 \mu \mathrm{g})$ and activator $(5 \mu \mathrm{g})$ plasmids were as in the legend to Fig. 1 . Activity of $100 \%$ represents 6,600 and 23,700 cpm, respectively. (B) Immunodetection of GAL4-c-Myb proteins in transfected cell extracts. Samples were analyzed by SDS-PAGE as described in Materials and methods and detected using a mixture of anti-Myb-2.2 and Myb-2.7 antibodies. Lines at left indicate molecular mass markers of $180,116,84,58,48,36$, and $26 \mathrm{kD}$, in descending order. 
Table 1. Deletions within the carboxyl terminus of $c-M y b$

\begin{tabular}{|c|c|c|c|}
\hline Deletion $^{a}$ & DNA sequence ${ }^{b}$ & $\begin{array}{l}\text { Amino acid } \\
\text { sequence }^{c}\end{array}$ & $\begin{array}{l}\text { Region } \\
\text { deleted }\end{array}$ \\
\hline d428-64l & TGT GGC TAG & Cys-Gly-Stp & Msc-end \\
\hline d463-641 & GAG CTA GAT & Glu-Leu-Asp-Lys & Sac-end \\
\hline d499-641 & GAT CCT AGA & Asp-Pro-Arg & Bgl-end \\
\hline $\mathrm{d} 367-427$ & CCT GAC CAC & Pro-Asp-His & Bsu-Msc \\
\hline $\mathrm{d} 425-464$ & CCA GCT CCA & Pro-Ala-Pro & PflM-Sac \\
\hline d463-497 & GAG $\mathrm{GAT}$ & Glu-Asp & Sac-Bgl \\
\hline d499-558 & GAT CAT GCA & Asp-His-Ala & $\mathrm{Bgl}-\mathrm{Nsi}$ \\
\hline d561-598 & GCA GCT AGC & Ala-Ala-Ser & Nsi-Nhe \\
\hline $\mathrm{d} 601-641$ & GCT AGC TAG & Ala-Ser-Stp & Nhe-end \\
\hline
\end{tabular}

${ }^{a}$ The chicken c-Myb amino acids deleted (d) in each mutant are given.

${ }^{b}$ The nucleotide sequence at the deletion junction is shown. Carets indicate the point of DNA fusion, except where an adaptor was used. The underlined nucleotide in the adaptor was added to bring the coding sequence in-frame. Codons through the deletion junction are separated by spaces.

${ }^{c}$ Amino acid sequence of the junction. Underlined amino acids are those not found in $\mathrm{c}-\mathrm{Myb}$. (Stp) Stop codon.

were constructed throughout the carboxy-terminal region (amino acids 367-641 of chicken c-Myb) to locate the negative regulatory region more precisely (Table 1 ). These deletions span the entire carboxy-terminal region deleted in the viral protein (amino acids 443-641 of chicken c-Myb). Transcriptional analysis by transient transfection of the appropriate activator and reporter plasmids into quail fibroblasts revealed that only one deletion (d499-558; BglII-NsiI) of the six tested resulted in any detectable activation of transcription by the GAL4-c-Myb fusion proteins (Fig. 2). None of the other five small deletions resulted in transcriptional activation, including the one that removes the predicted $\mathrm{Myb}$ leucine zipper (d367-427 ). Internal deletion of an amino acid sequence (amino acids 425-464; PflMI-SacI), almost identical to the region necessary for strong negative regulation (amino acids 428-462) that was identified by progressive truncation, had no effect on transcriptional activation. These experiments therefore suggested that the carboxyl terminus of c-Myb contains a distal regulatory sequence carboxy-terminal to amino acid 499 and a proximal regulatory sequence between amino acids 428 and 462 (MscI-SacI), either of which is sufficient for strong negative regulation in cis. Simultaneous deletion of both regions resulted in $\sim 60 \%$ of the activity of the most active carboxy-terminal truncation (d428-641), demonstrating that each of the regions can function independently as a negative regulatory element (Fig. 2).

The c-Myb carboxyl terminus inhibits trans-activation in vivo, not DNA binding

To assess the effect of the carboxyl terminus on nuclear transport and DNA binding in vivo, we also made a fu- sion of the carboxy-terminal portion of c-Myb with the bacterial repressor LexA. Fusions of this type have been used to demonstrate in vivo DNA binding of chimeric proteins to repressible promoters in animal cells (Godowski et al. 1988; Martin et al. 1990). This LexAc-Myb fusion protein is analogous to the GAL4-c-Myb fusion except that the 147-amino-acid GAL4 DNA-binding domain was replaced by the 202 amino acids of LexA. A second construct was made by deleting the carboxyl terminus of c-Myb from the LexA fusion protein near the position of viral truncation. The in vivo DNA-binding (repression) assay was performed with reporter plasmids containing the SV40 promoter/enhancer driving CAT gene expression. The test plasmid contained one Lex operator positioned near the site of transcription initiation, whereas the control plasmid contained no Lex operator sites (Fig. 3). Thus, LexA proteins should bind to the Lex operator of the test plasmid and repress transcription from the SV40-Lex promoter, but not from the SV40 promoter of the control plasmid.

Because the LexA fusion proteins were used as a model to assess the effect of carboxy-terminal truncation on in vivo DNA binding, it was important to confirm that they demonstrated the same relative transcriptional activation behavior as the GAL4-c-Myb fusions. The same LexA-c-Myb fusions were therefore tested, along with the GAL4 and LexA DNA-binding domains alone, for transcriptional activation activity using the Elb TATACAT reporter plasmid with or without six upstream Lex sites (Fig. 3). Lex site-dependent transcriptional activation was not observed with the GAL4 DNA-binding domain [GAL4(DBD|], LexA, or the full-length LexA fusion (LexA-CC), but strong activation was seen with the truncated fusion (LexA-Cd). These results were similar to those obtained with the corresponding GAL4 fusion proteins [GAL4-CC and GAL4-Cd (d428-641); see Fig. 2) and the GAL4 reporter plasmid. Immunoblotting of transfected cell extracts (Fig. 3) showed the presence of similar levels of LexA-c-Myb fusion proteins of the expected molecular weights.

Plasmids encoding the LexA DNA-binding domain (LexA), the full-length fusion protein (LexA-CC), the truncated fusion protein (LexA-Cd), and GAL4(DBD) were each cotransfected with either the test plasmid (SV40-Lex-CAT) or the control plasmid (SV40-CAT). The GAL4(DBD) protein should not affect transcription from either reporter and would therefore result in constitutive CAT expression levels against which to compare the LexA and LexA-c-Myb fusion proteins. Transcription from the control plasmid, SV40-CAT, was reduced somewhat in the presence of the LexA proteins relative to the GAL4(DBD) (Fig. 3). Perhaps there is a cryptic Lex operator in the SV40 promoter/enhancer region. However, all three LexA-containing proteins greatly reduced the level of transcription from the SV40Lex-CAT plasmid, relative to GAL4(DBD). These results showed that the repression was dependent on the presence of both the LexA DNA-binding domain and Lex operator sequences. Expression of the CAT gene from the test plasmid containing the Lex operator relative to 


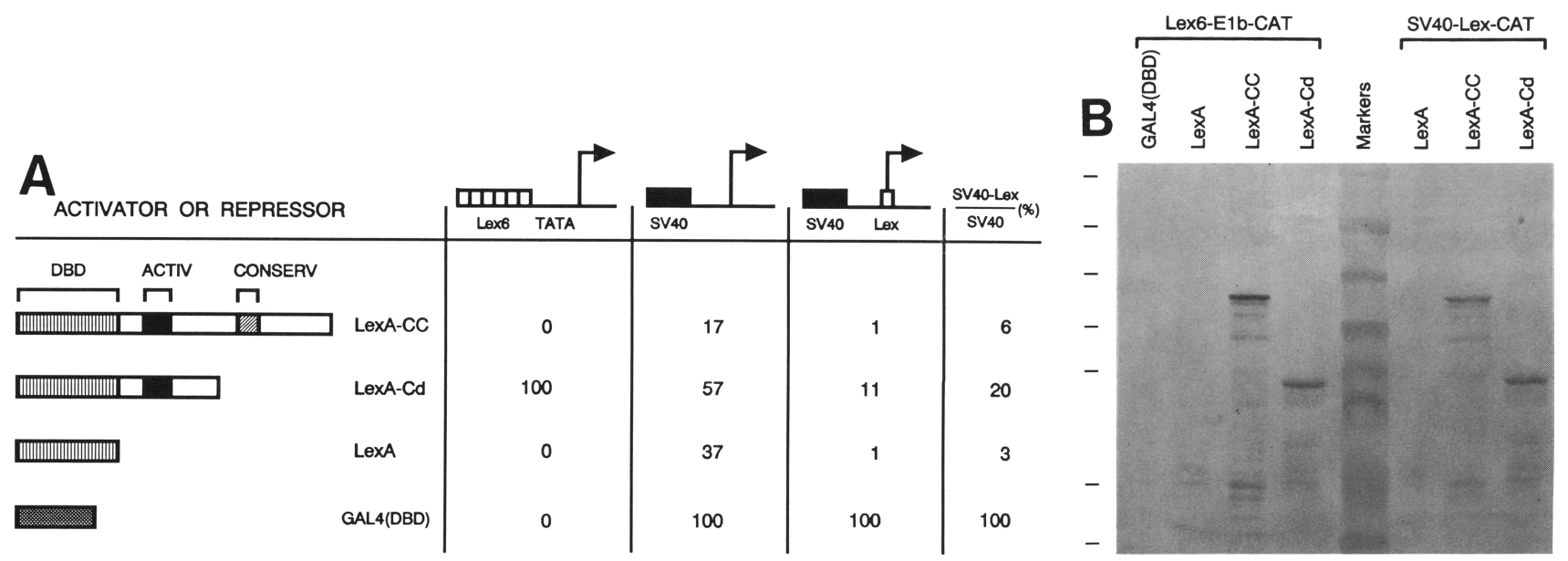

Figure 3. Effect of the c-Myb carboxyl terminus in cis on in vivo LexA-c-Myb DNA binding. (A) Activator activities (first column) are shown relative to the strongest activator from the Lex6-EIb-CAT reporter, LexA-Cd. Transcription from the SV40-CAT /second column) or SV40-Lex-CAT reporter (third column) in the presence of LexA proteins is shown as a percent of transcription in the presence of GAL4/DBD). The percent of normalized transcription from SV40-Lex-CAT relative to that from SV40-CAT for each protein is shown in the fourth column. Schematics show the proteins with c-Myb sequences indicated as in Fig. 2. Transfections included reporter $(1 \mu \mathrm{g})$ and activator or repressor plasmid $(3 \mu \mathrm{g})$. Activity of $100 \%$ represents $16,300,63,900$, and $98,100 \mathrm{cpm}$, respectively. $(B)$ Immunodetection of LexA-c-Myb fusions in transfected cell extracts. Immunoblotting was performed as in the legend to Fig. 2, but with anti-Myb-2.7 antibody. Molecular mass markers are as in Fig. 2, except in the center of the gel.

expression from the control plasmid for each protein is taken as a measure of repression (Fig. 3). Transcription from SV40-Lex-CAT was significantly repressed in cells containing the LexA DNA-binding domain $197 \%$ repressed| and the full-length LexA-c-Myb fusion protein, LexA-CC (94\% repressed). The truncated fusion protein, LexA-Cd, gave somewhat higher levels of CAT expression $(80 \%$ repressed) in cells cotransfected with the test plasmid than did either LexA or LexA-CC. The apparently incomplete repression by LexA-Cd may be the result of some transcription being stimulated by the highly active LexA-Cd protein even when bound at the usual initiation site of the promoter. Expression of similar levels of both LexA-c-Myb fusion proteins was confirmed by Western blotting of cell extracts (Fig. 3). The fulllength and truncated LexA-c-Myb fusion proteins thus behaved in an opposite manner from that expected if the carboxyl terminus simply inhibited DNA binding. These results suggest that the carboxy-terminal sequences negatively regulate transcriptional activation by affecting a step subsequent to DNA binding.

The carboxyl terminus of $c-M y b$ inhibits

transcriptional activation by $\mathrm{V} \cdot \mathrm{My} b$ or $a \mathrm{~V}-\mathrm{My} b$ VP16 fusion in trans

We also tested the ability of c-Myb carboxy-terminal sequences in trans to affect transcription levels stimulated by v-Myb. A proviral vector that expresses v-Myb was cotransfected with the Myb-responsive Elb TATA/CAT gene reporter and plasmids that express different parts of the c-Myb protein (Fig. 4). Cotransfection with DNA encoding $\mathrm{c}-\mathrm{Myb}$ proteins that contained the carboxyl ter- minus significantly inhibited $\mathrm{v}-\mathrm{Myb}$ transcriptional activation relative to vector DNA lacking any c-Myb-coding sequence. The level of inhibition by the carboxyl terminus was similar whether $(\mathrm{CCC})$ or not $(\mathrm{dCC})$ the amino terminus was present. The doubly truncated c-Myb protein (dCd) resulted in no inhibition, whereas the singly truncated proteins $\mathrm{dCC}$ and $\mathrm{CCd}$ resulted in strong and moderate inhibition of v-Myb activation, re-

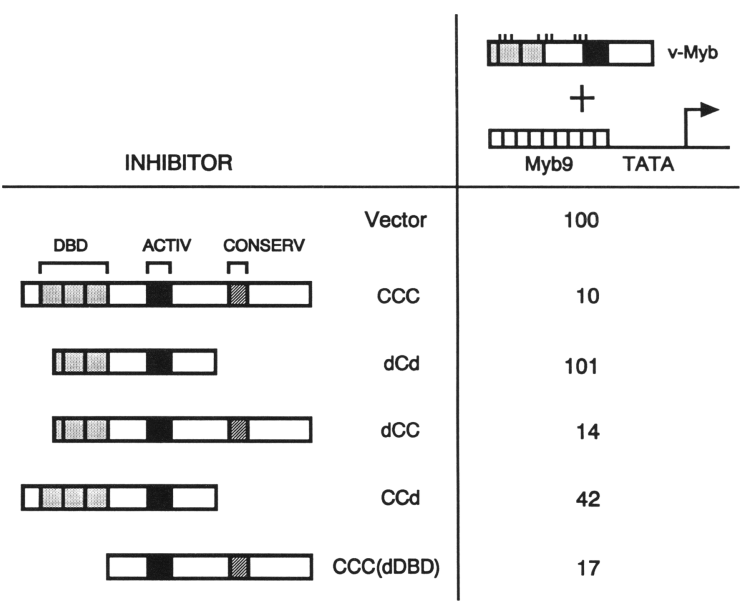

Figure 4. Effect of $\mathrm{c}-\mathrm{Myb}$ sequences in trans on transcription in the presence of $\mathrm{v}-\mathrm{Myb}$. Activities are shown relative to $\mathrm{v}-\mathrm{Myb}$ in the absence of $\mathrm{c}-\mathrm{Myb}$ (Vector). Schematics show protein sequences as in Fig. 1, except experiments included v-Myb along with reporter as shown (top). Transfections included reporter (1 $\mu \mathrm{g})$, and plasmids expressing $\mathrm{v}-\mathrm{Myb}(3 \mu \mathrm{g})$ and different parts of c-Myb $(3 \mu \mathrm{g})$ as described. Activity of $100 \%$ equals $19,900 \mathrm{cpm}$. 
spectively. The results of this experiment were complicated by the fact that the c-Myb proteins used as inhibitors can also bind to Myb-binding sites. This binding might result in a complex composite reaction by the $\mathrm{c}-\mathrm{Myb}$ protein being tested, reflecting both its own transcriptional activating activity and its inhibition of $\mathrm{v}-\mathrm{Myb}$ transcriptional activation. Therefore a c-Myb protein from which the DNA-binding domain had been deleted was also tested. Transcriptional activation was inhibited as strongly by this protein, $C C C(\mathrm{dDBD})$, as by the other $\mathrm{c}-\mathrm{Myb}$ proteins containing the carboxyl terminus, providing strong evidence that c-Myb was inhibiting $\mathrm{v}-\mathrm{Myb}$ activation in trans. As seen with the simple activation experiments using different $\mathrm{c}-\mathrm{Myb}$ proteins to examine negative regulation in cis (Fig. 1), the ability to inhibit v-Myb transcriptional activation activity in trans localized to the carboxyl terminus of c-Myb.

We tested a v-Myb-VP16 fusion to determine whether trans-inhibition would operate on a strong heterologous transcriptional activation domain (Triezenberg et al. 1988). The fusion was made at a site in v-Myb within its transcriptional activation domain and is referred to as the v-Myb-VPl6 fusion protein (VVP) (Ibanez and Lipsick 1990). Truncation of native v-Myb at this site abolishes transformation and transcriptional activation [LX2 (Ibanez and Lipsick 1988, 1990)]. When expressed from a proviral vector, this VVP fusion protein stimulated high levels of transcription from a reporter plasmid containing Myb-binding sites in front of the E1b TATA/ CAT gene combination but not from a reporter without Myb-binding sites (Grasser et al. 1992). The high activity of the VVP protein required less DNA for each transfection and resulted in a greater range of activation over which to examine inhibition. c-Myb inhibited VVP activity by at least $80 \%$ at plasmid ratios between $0.3: 1$ and $30: 1$ (data not shown). All of those c-Myb proteins (CCC, dCC, GAL4-CC) that contain the carboxyl terminus strongly inhibited activation by VVP, whereas both $c-M y b$ proteins that lack carboxy-terminal sequences (CCd and dCd) failed to inhibit VVP activity signifi- cantly (data not shown). Although it is unable to bind Myb-binding sites, the GAL4-c-Myb fusion protein was able to strongly inhibit VVP transcriptional activation (Fig. 5). Furthermore, the DNA-binding domain deletion of c-Myb [CCC(dDBD)] also inhibited VVP (data not shown|. These results demonstrate that inhibition of VVP activity by the carboxy-terminal sequence of c-Myb was not due simply to competition between the c- and $\mathrm{v}-\mathrm{Myb}$ molecules for Myb-binding sites on the reporter DNA. We refer to trans-inhibition as "suppression" to distinguish it from negative regulation in cis. The region of $\mathrm{c}-\mathrm{Myb}$ that performs this suppression is defined as having suppressor activity, and the region of $\mathrm{v}-\mathrm{Myb}$ necessary for inhibition is called the target of suppression.

\section{Suppression by c-Myb maps to one of the carboxy-terminal negative regulatory elements}

The six carboxy-terminal deletions of the GAL4-c-Myb fusion protein previously tested for transcriptional activation were used to identify the region in the $c-M y b$ carboxyl terminus required to suppress VVP activity in trans. Each of these deletion constructs was cotransfected along with VVP and the reporter plasmid containing upstream Myb-binding sites. Figure 5 shows that all of the deletions except d499-558 (BgIII-NsiI) were capable of suppressing VVP activity. Specifically, deletion of the heptad leucine repeat sequence located between amino acids 376 and 404 of the chicken c-Myb sequence had no effect on suppressor activity (see d $367-427^{\circ}$ in Fig. 5). Immunoblot analysis of the same cells assayed for CAT activity demonstrated the presence of similar levels of the expected GAL4-c-Myb fusion proteins (Fig. 5). Deletion of amino acids 499-558 from GAL4-CC increased transcriptional activation by VVP to between 55 and $70 \%$ of uninhibited levels in different experiments. It is interesting that the amino acid 499-558 region might function both in the trans-inhibition (suppression) of $\mathrm{v}-\mathrm{Myb}-\mathrm{VP} 16$ transcriptional activation (Fig. 5) and in
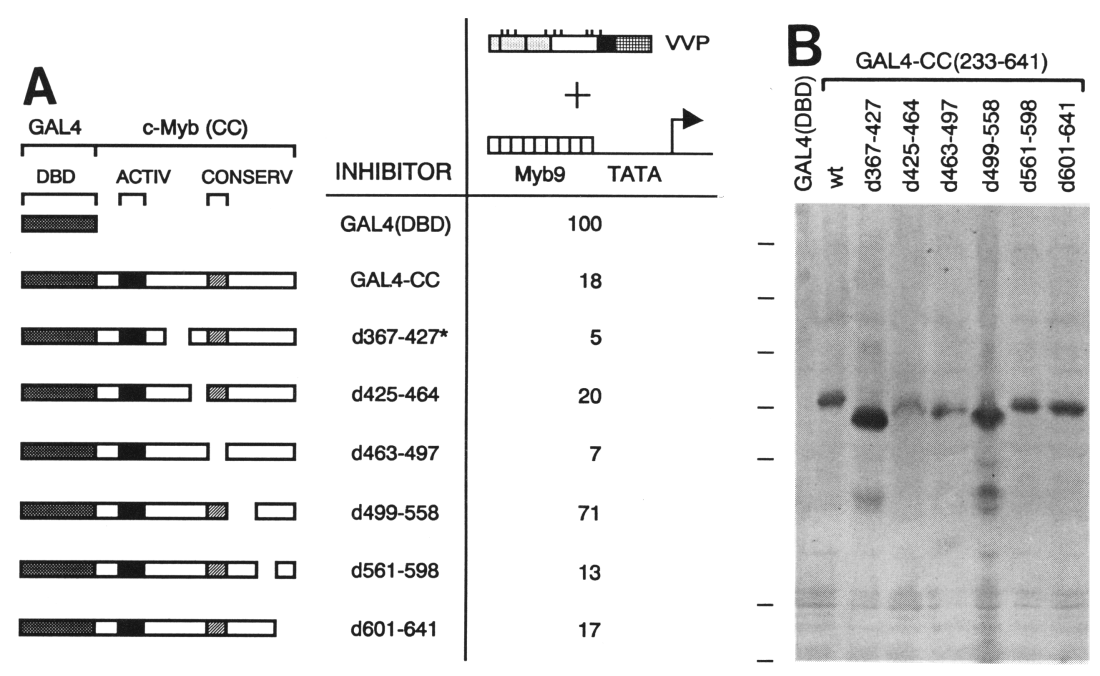

Figure 5. Mapping of c-Myb carboxy-terminal elements responsible for trans-inhibition. (A) Activities are shown relative to VVP in the presence of the GAL4(DBD). Schematics show protein sequences as in Fig. 2, except experiments included VVP and reporter that contained Myb-binding sites (top). The asterisk $\left({ }^{*}\right)$ indicates the deletion that removes the potential Myb leucine zipper structure. Transfections included reporter $(1 \mu \mathrm{g})$, and plasmids expressing VVP $(0.1 \mu \mathrm{g})$ and different GAL4-CC deletion mutants $(3 \mu \mathrm{g})$ as described. Activity of $100 \%$ equals $70,500 \mathrm{cpm}$. (B) Immunodetection of GAL4-c-Myb proteins in transfected-cell extracts. Immunoblotting was performed, and markers are the same as in the legend to Fig. 2. 
the negative regulation of its own transcriptional activity in cis (Fig. 2).

\section{A specific sequence in the Myb activation domain functions as a target of suppression}

To determine the region in $\mathrm{v}-\mathrm{Myb}$ that was the target of suppression, we constructed deletions of $\mathrm{v}-\mathrm{Myb}$ and VVP and tested them for their ability to be inhibited in trans by GAL4-c-Myb (Fig. 6). Most deletions of native v-Myb abolish transcriptional activation activity (Ibanez and Lipsick 1990; R.-H. Chen and J. Lipsick, unpubl.), even if they retain the minimal transcriptional activation domain defined by previous GAL4-v-Myb fusion studies (Weston and Bishop 1989). Because these v-Myb deletion proteins have no intrinsic activity, it is not possible to test them as targets for suppression. However, we constructed a deletion of a less well-conserved region, whose amino acid sequence suggests random coil character, located between the DNA-binding and transcriptional activation domains. A v-Myb mutant that was deleted of this possible "hinge" region $(\mathrm{v}-\mathrm{Myb}-\mathrm{dH}$ ) retained $\sim 50 \%$ of wild-type transcriptional activation activity (Fig. 6). Stimulation of transcription from the Myb-binding site reporter plasmid by this $\mathrm{v}-\mathrm{Myb}-\mathrm{dH}$ mutant was strongly suppressed by the full length GAL4-c-Myb fusion protein, as was wild-type v-Myb (Fig. 6). Both the transactivating protein ( $\mathrm{v}-\mathrm{Myb}$ or $\mathrm{v}-\mathrm{Myb}-\mathrm{dH}$ ) and the suppressing protein (GAL4-CC) were detected by immunoblotting of the same cells tested for CAT activity (Fig. 6).
These results indicated that the target of suppression must be in another part of the v-Myb protein, in the DNAbinding region, transcriptional activation region, or both.

Because other v-Myb deletions fail to trans-activate, the v-Myb-VP16 fusion protein was used to further map the target sequence. The VVP protein was suppressed by c-Myb even though it is missing the putative heptad leucine repeat. Therefore, the leucine repeat on the target molecule is not involved in suppression. A deletion of the region corresponding to amino acids 169-239 of $\mathrm{v}-\mathrm{Myb}$ between SmaI (XmaI) and HincII (SalI) sites in VVP was constructed (VVP-dTA) that removes the remainder of a negatively charged region implicated in transcriptional activation by v-Myb. This yields a protein consisting essentially of the v-Myb DNA-binding domain fused to the VP16 trans-activating sequence (Fig. 6). When tested for suppression by the c-Myb carboxyterminal sequence, the VVP-dTA protein exhibited the same high activation levels in the presence of the GAL4 CC fusion protein or GAL4(DBD) alone (Fig. 6). Western blots using extracts from the same cells as those assayed for CAT activity showed that lack of suppression was not the result of the absence of the GAL4-CC protein (Fig. 6). The v-Myb DNA-binding domain alone is therefore not sufficient to function as a target of suppression, nor is the VP16 transcriptional activation domain alone a sufficient target. Rather, amino acids in the transcriptional activation domain of the $\mathrm{v}$-Myb sequence between amino acids 169 and 239 (SmaI-HincII) are necessary for suppression by c-Myb.

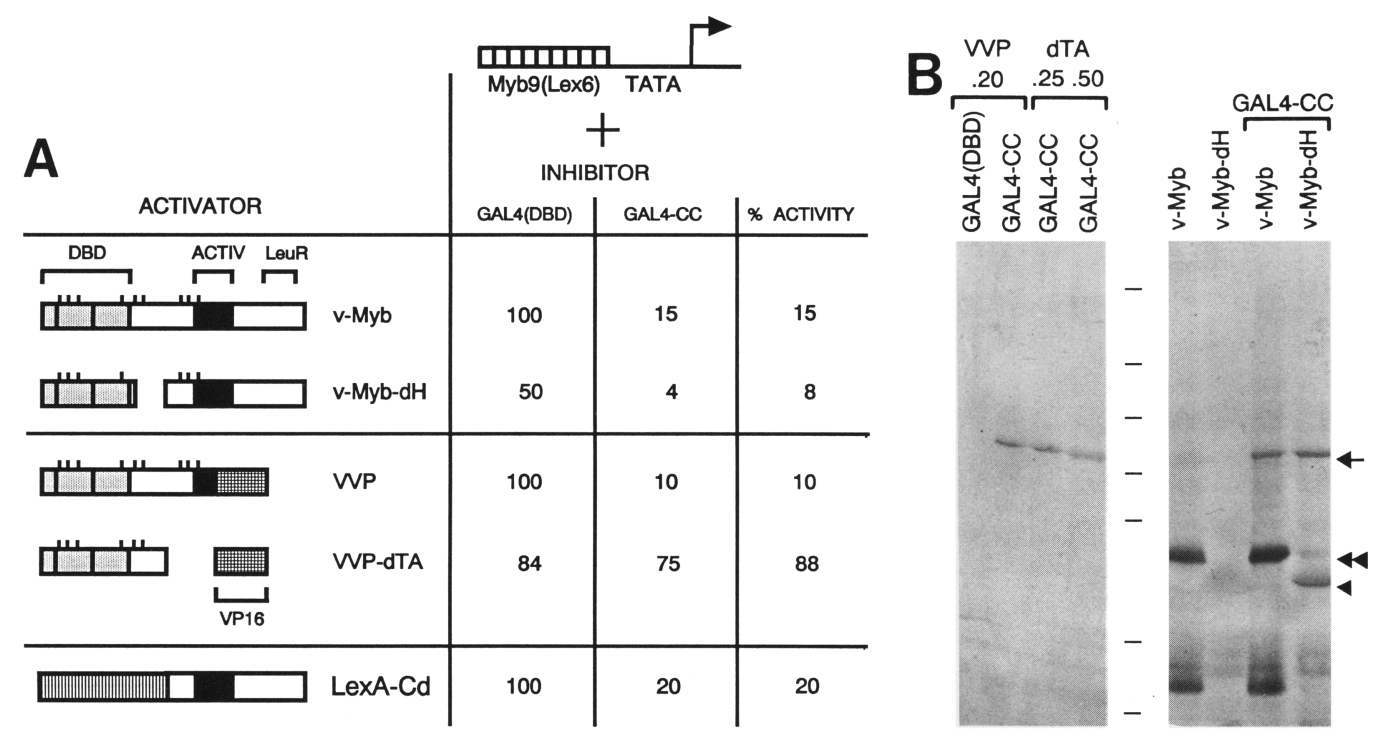

Figure 6. Mapping of Myb target sequences that mediate trans-inhibition. (A) Activities are shown relative to each wild-type protein in the presence of GAL4(DBD) (left column). Schematics show protein sequences and reporter plasmid as in previous figures. Transfections included reporter ( $1 \mu \mathrm{g})$, and plasmids expressing v-Myb $(5 \mu \mathrm{g}), \mathrm{v}-\mathrm{Myb}-\mathrm{dH}(5 \mu \mathrm{g}), \mathrm{VVP}(0.2 \mu \mathrm{g}), \mathrm{VVP}-\mathrm{dTA}(0.5 \mu \mathrm{g})$, or LexA-Cd $(3 \mu \mathrm{g})$, and GAL4(DBD) or GAL4-c-Myb $(3 \mu \mathrm{g})$ as described. Results from the transfection of $0.25 \mu \mathrm{g}$ of VVP-dTA (data not shown) were similar to those using $0.5 \mu \mathrm{g}$. Activity of $100 \%$ represents v-Myb, 10,000; VVP, 26,500; and LexA-Cd, 39,400 cpm. (B) Immunodetection of Myb and Myb fusions in transfected cell extracts. Immunoblotting was performed as in Fig. 2. VP16 fusion proteins are not detected owing to the low amount of plasmid transfected. The positions of $\mathrm{v}-\mathrm{Myb}$ (double arrowhead), $\mathrm{v}-\mathrm{Myb}-\mathrm{dH}$ (single arrowhead), and GAL4-c-Myb (arrow) are indicated. Fig. 3B shows the stable production of immunoreactive LexA-Cd protein of the expected molecular mass. 
To determine whether the Myb DNA-binding domain itself was necessary for suppression, we tested the highly active LexA-Cd protein for suppression by GAL4-CC. Neither of these proteins contains a Myb DNA-binding domain; furthermore, the use of LexA-Cd allowed us to assess the suppressibility of a c-Myb transcriptional activation domain. The activation domain of $c-M y b$ differs from that of $\mathrm{v}$-Myb by three amino acid substitutions. Figure 6 shows that transcriptional activation by LexACd from the Lex site reporter was inhibited by GAL4 CC relative to GAL4(DBD), the GAL4 DNA-binding domain alone. This result demonstrated that the process of suppression does not require a Myb DNA-binding domain on either protein. In addition, the c-Myb activation domain of LexA-Cd is also capable of being suppressed, despite the three different amino acids in the target sequence.

\section{Discussion}

The differences between the transforming oncoprotein $\mathrm{v}-\mathrm{Myb}$ and its normal cellular counterpart, c-Myb, are responsible for the oncogenicity of the virus AMV. Deletion of either one or both ends of the c-Myb protein, which are absent in v-Myb, has been shown to be sufficient for activation of its transforming potential /Grasser et al. 1991). Deletion of the carboxyl terminus of c-Myb also markedly increases its transcriptional activation capacity (Sakura et al. 1989; Kalkbrenner et al. 1990) (Fig. 1). Previous work from a number of laboratories has attempted to define the elements necessary for negative regulation of c-Myb transcriptional activity (Sakura et al. 1989; Kalkbrenner et al. 1990; Hu et al. 1991; Kanei-Ishii et al. 1992). We undertook the present study to investigate the role of specific carboxy-terminal domains in this regulation.

Our results show that no single small deletion within the carboxyl terminus results in the large increase in transcriptional activation activity observed with carboxy-terminal truncations extending upstream of amino acid 463 (Fig. 2). In contrast to the results of Kanei-Ishii et al. (1992), deletion of the region containing the heptad leucine repeat structure did not increase transcriptional activation above background, suggesting that it is not involved in the negative regulation examined here. Internal deletion of amino acids $499-558$ was the only one that increased transcription by itself, albeit modestly. These results suggest that cis negative regulatory function exists in at least two regions of the c-Myb carboxyl terminus, either of which is sufficient. Although internal deletion of the more carboxy-terminal element (amino acids 499-558) increased transcription only slightly, removal of this region by truncation from the carboxyl terminus does activate a low level of transformation (Grasser et al. 1991; Hu et al. 1991), providing additional evidence that amino acids 499-558 may indeed be involved in negative regulation. The large increase in transcriptional activation observed upon simultaneous deletion of both regions implicated in negative regulation (d425-464 + 499-558) confirmed that either region can function as a strong negative regulatory element in the absence of the other. These experiments also resolve the discrepancy between previous reports that had assigned the negative regulatory domain to different nonoverlapping regions (Sakura et al. 1989; Kalkbrenner et al. 1990; Hu et al. 1991). In addition, a sequence in the carboxyl terminus of c-Myb can negatively regulate transcriptional activation by v-Myb, or by a v-Myb-VP16 or LexA-c-Myb fusion protein in trans, a process we refer to as suppression. Suppressor activity correlates with one of the cis-acting negative regulatory regions and is independent of DNA binding by c-Myb. The target of suppression is a Myb sequence containing part of the transcriptional activation domain. Suppression does not require the presence of the Myb DNA-binding domain on either molecule.

These results provide evidence of a possibly complex domain organization of the carboxy-terminal region of c-Myb. Interestingly, an amino acid sequence within each negative regulatory region appears to be conserved in a number of Myb-related proteins, including the yeast BAS1 protein, which was previously believed to have homology only to the Myb DNA-binding domain (TiceBaldwin et al. 1989) (Table 2). In BAS1 the two regions of homology occur in the inverse order relative to $\mathrm{c}-\mathrm{Myb}$, suggesting that they may be modular in nature. Because the amino acid 499-558 deletion was one of the largest used in this study (60 amino acids) and deletions may result in gross overall structural changes, smaller deletions through this domain might provide more detailed information. Additionally, less disruptive linker insertion mutations throughout the entire carboxyl terminus may reveal even more complexity in the domain structure of the carboxy-terminal region.

The presence of the carboxyl terminus in cis seems to have little, if any, effect on in vivo DNA binding by a LexA-c-Myb fusion protein, although it strongly inhibits transcriptional activation. Ramsay et al. (1991, 1992) suggested that carboxy-terminal truncation may activate c-Myb in part by increasing its affinity for Myb-binding sites. We have also reported a progressive increase in $\mathrm{v}-\mathrm{Myb}$ DNA binding that parallels progressive truncation from the carboxyl terminus (Garcia et al. 1991). Perhaps these distal amino acid sequences sterically hinder or perturb the structure of the Myb DNA-binding domain. However, although it remains possible that changes in DNA-binding affinity play a part in the activation of c-Myb by carboxy-terminal truncation, the action of the cis negative regulatory domains described in this paper does not involve inhibition of DNA binding.

Negative regulation by the c-Myb carboxyl terminus also functions in trans to suppress transcriptional activation by v-Myb, v-Myb-VP16, or a truncated LexA-cMyb protein, LexA-Cd. Binding to DNA by the protein bearing the c-Myb carboxy-terminal suppressor sequence is not required for this suppression. DNA-binding independent suppression by the carboxyl terminus eliminates competition for Myb-binding sites on the reporter plasmid as a possible mechanism. Therefore, proteinprotein interactions are most likely involved. There are 
Table 2. Alignment of carboxy-terminal domains of vertebrate Myb-related proteins and yeast BAS1

\section{Alignment 1}

\author{
HumC $451-480$ \\ ChiC $452-481$ \\ HumA 540-569 \\ BAS1 $524-553$
}

HumC 499-533

ChiC 500-534

HumA 585-623

BAS1 278-312

\begin{abstract}
$\begin{array}{lllllllllllllllllllllllllllllll}\mathbf{R} & \mathbf{T} & \mathbf{P} & \mathrm{A} & \mathrm{I} & \mathrm{K} & \mathbf{R} & \mathrm{S} & \mathrm{I} & \mathbf{L} & \mathbf{E} & \mathrm{S} & \mathrm{S} & \mathrm{P} & \mathbf{R} & \mathrm{T} & \mathbf{P} & \mathrm{T} & \mathrm{P} & \mathrm{F} & \mathrm{K} & \mathrm{H} & \mathbf{A} & \mathbf{L} & \mathbf{A} & \mathbf{A} & \mathbf{Q} & \mathbf{E} & \mathrm{I} & \mathrm{K}\end{array}$

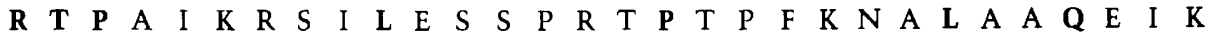

$\begin{array}{llllllllllllllllllllllllllllll}\mathbf{R} & \mathbf{T} & \mathbf{P} & \mathbf{R} & \mathrm{I} & \mathbf{R} & \mathbf{R} & \mathrm{S} & \mathrm{I} & \mathbf{L} & \mathrm{G} & \mathrm{T} & \mathrm{T} & \mathbf{P} & \mathbf{R} & \mathrm{T} & \mathbf{P} & \mathrm{T} & \mathbf{P} & \mathbf{R} & \mathrm{K} & \mathbf{N} & \mathbf{A} & \mathbf{L} & \mathbf{A} & \mathbf{A} & \mathbf{Q} & \mathbf{E} & \mathrm{K} & \mathrm{K}\end{array}$

$\begin{array}{llllllllllllllllllllllllllllll}\mathbf{R} & \mathbf{T} & \mathbf{P} & \mathrm{N} & \mathrm{Y} & \mathrm{N} & \mathrm{A} & \mathrm{F} & \mathrm{S} & \mathbf{L} & \mathrm{E} & \mathrm{A} & \mathrm{T} & \mathrm{S} & \mathrm{H} & \mathrm{N} & \mathbf{P} & \mathrm{A} & \mathrm{D} & \mathrm{N} & \mathrm{A} & \mathrm{N} & \mathrm{E} & \mathbf{L} & \mathrm{G} & \mathrm{S} & \mathbf{Q} & \mathrm{S} & \mathbf{N} & \mathbf{R}\end{array}$

$* *$ *
\end{abstract}

\section{Alignment 2}

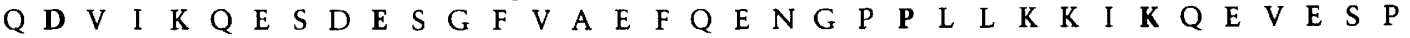

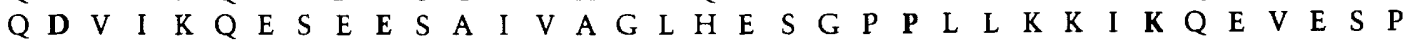

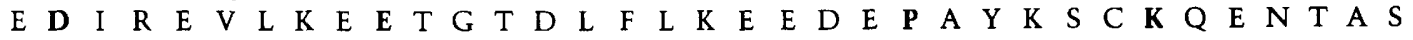
$\begin{array}{llllllllllllllllllllllllllllllllllll}Q & D & I & L & N & V & K & E & N & E & S & S & K & L & P & R & L & K & D & N & D & G & P & I & L & N & D & S & K & P & Q & A & L & P & P\end{array}$ * 0 O * 0 * 0 .

Amino acid sequences of two regions in several Myb-related proteins are shown using the standard single-letter code. The residue numbers for each protein segment compared in the two alignments are given. Alignments were performed with the MACAW computer program (Schuler et al. 1991), kindly provided to us by Eric Westin.

Boldface type indicates identity of a residue in all four sequences.

(*) Identity of a BASI residue with the same position in at least two other sequences.

(O) Similarity of a BASI residue with the same position in at least two other sequences.

many possible models to explain how such interactions might operate (Fig. 7). First, the interaction between the c-Myb suppressor and Myb acidic target domains may be direct. It could be relevant that several potentially basic amino acid segments have been found in appropriate regions of the c-Myb carboxyl terminus (Gonda et al. 1985). Second, the regulatory state could be modulated by the phosphorylation of either or both domains. There are several known or postulated phosphorylation sites in appropriate regions of $\mathrm{c}-\mathrm{Myb}$. Third, the negative regulatory region of $\mathrm{c}-\mathrm{Myb}$ might contain a binding site for a small effector molecule, such as a hormone or vitamin. The activation of c-Myb by carboxy-terminal truncation does resemble that of the steroid hormone receptor, in

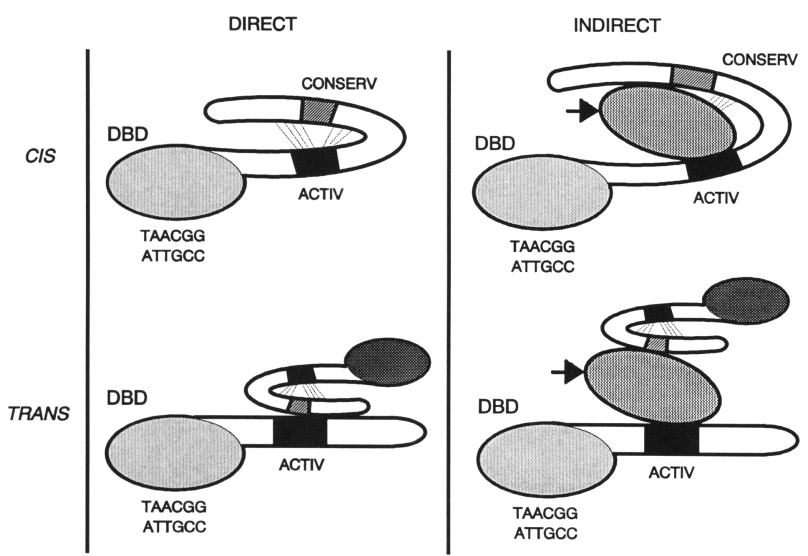

Figure 7. Models for regulation by the carboxyl terminus of c-Myb in cis and trans. The examples shown are c-Myb (cis) and suppression of $\mathrm{v}$-Myb by GAL4-c-Myb (trans), with domains shaded as in previous figures. Indirect regulation is shown by including an ancillary protein in the model (arrows). Other modes of indirect regulation such as phosphorylation and hormone binding are discussed in the text. that deletion of the hormone-binding domain also creates a constitutively active receptor (Evans 1988). Finally, regulation could be facilitated by ancillary proteins that specifically interact with the Myb functional domains. The action of such accessory proteins would be similar to the adaptors proposed to mediate interaction between some DNA-binding transcription factors and the general transcription machinery (Pugh and Tjian 1990). It is also possible that two or more of these mechanisms function in concert.

Mapping of the domains required for suppression indicates that a sequence in the downstream carboxy-terminal negative regulatory element (amino acids 499-558) contains most of the suppressor activity (Fig. 5). Small amounts of additional suppressor activity residing in other regions may have escaped detection. A predicted Myb leucine zipper structure (Biedenkapp et al. 1988) present in the GAL4-c-Myb fusion protein appears to be unnecessary for suppressor function. Because the suppressible target v-Myb-VP16 lacks the potential Myb leucine zipper, this sequence is not involved in suppression either on the target molecule or on the carboxyterminal suppressor sequence. The Myb sequence that does function as the target for suppression (amino acids 169-239; Fig. 6) includes the upstream two-thirds of the region defined as the minimal transcriptional activation domain (Weston and Bishop 1989). Although this sequence contains most of the acidic character of the domain and is necessary as a target for suppression, it is not sufficient to support transcriptional activation either as a GAL4 fusion (Weston and Bishop 1989) or as the carboxy-terminal part of a nontransforming, truncated native v-Myb molecule [LX2 (Ibanez and Lipsick 1988, 1990)].

A model consistent with our results would include a c-Myb carboxy-terminal interaction mediated by one part of the Myb transcriptional activation sequence and 
the "poisoning" of another part responsible for activation activity. In the case of v-Myb-VP16, the adjacent VP16 activation domain would be suppressed in an analogous way. Apparently, this process can tolerate the three amino acid changes present in the c-Myb activation domain of LexA-Cd. The carboxy-terminal sequences that perform these binding and poisoning functions would be "pseudosubstrates," resembling the sequences on the protein molecules, such as adaptors or transcription machinery, that normally mediate transcriptional activation by Myb in the absence of negative regulation. Alternatively, the carboxyl terminus of c-Myb may suppress multiple classes of transcriptional activation domain by a general mechanism such as steric hinderance. In any case, the results presented here and previously (Ibanez and Lipsick 1988, 1990) imply that the structure-function relationships of the Myb transcriptional activation domain may also be complex.

Interestingly, Grasser et al. (1991) observed suppression of $\mathrm{v}-$ Myb transformation by the c-Myb carboxyl terminus in cis. The data reported in the present paper suggest that suppression in trans may have the same effect, a possibility supported by the fact that cell lines transformed by $\mathrm{v}-\mathrm{Myb}$ or by truncated forms of $\mathrm{c}-\mathrm{Myb}$ express little or no detectable full-length c-Myb (Lipsick 1987; Ramsay et al. 1989; Grasser et al. 1991). Thus, suppression of $\mathrm{v}$-Myb activity by the c-Myb protein might constrain transformation to those precursor cells whose differentiation has progressed to the point that c-Myb expression has been shut off. The presence of an additional carboxy-terminal exon in some forms of murine and human c-Myb (for review, see Shen-Ong 1990) might alter their suppression activity or specificity. Human A- and B-Myb proteins that contain sequences homologous to this alternative exon have been found coexpressed with the normal c-Myb protein (Nomura et al. 1988). These classes of cellular Myb could interact with each other to suppress activity under different conditions of growth or differentiation.

In this paper we show that the c-Myb carboxyl terminus contains functionally complex sequences capable of negatively regulating Myb transcriptional activity both in cis and in trans. Regulation in cis could actually be an intermolecular reaction in which two Myb molecules bind together and mutually inhibit transcriptional activation. Regulation in trans, or suppression, does not require DNA binding by the carboxy-terminal sequence and probably involves specific protein-protein interactions. The Myb DNA-binding domain is not required on either the suppressor or target protein. Our results do not distinguish between alternative direct or indirect interaction (Fig. 7). The heptad leucine repeat structure is apparently not involved in suppression, but it is possible that the use of a GAL4-c-Myb fusion precludes detection of the cis participation of this motif. The fact that the $\mathrm{v}-\mathrm{Myb}$ target sequence is necessary for suppression of a heterologous activation domain suggests that transcriptional activation and suppression are specified by somewhat different amino acid sequences. Suppression represents a novel form of transcriptional regulation in trans and may also operate within other classes of transcriptional activator.

\section{Materials and methods}

\section{Plasmid constructions}

DNA restriction and modifying enzymes were purchased from New England Biolabs (Beverly, MA). Oligonucleotide adaptors and primers were made on an Applied Biosystems (Foster City, CA) model 380B synthesizer. Recombinant DNA manipulations were carried out using standard techniques (Maniatis et al. 1982). Retroviral constructions that express $\mathbf{v}-\mathrm{Myb}$ (dGE), $\mathrm{c}-\mathrm{Myb}$, and $\mathrm{c}-\mathrm{Myb}$ truncations have been described previously (Ibanez and Lipsick 1988; Grasser et al. 1991). Single and double truncations of $\mathrm{c}-\mathrm{Myb}$ are named according to the sequences present $\langle\mathrm{C}\rangle$ or absent $(\mathrm{d})$ relative to the $\mathrm{v}-\mathrm{Myb}$-coding sequence. Thus, the c-Myb proteins deleted of the amino-terminal, carboxy-terminal, or both sequences missing in $\mathrm{v}-\mathrm{Myb}$ are referred to as $\mathrm{dCC}, \mathrm{CCd}$, or $\mathrm{dCd}$, respectively. Expression of the v-MybVP16 fusion protein (VVP) used in this study has been described previously (Ibanez and Lipsick 1990).

Deletions within the carboxyl terminus of c-Myb were constructed by blunt-end ligation of the appropriately restricted and Klenow-treated DNA where such treatment would give inframe deletions (Table 1). For the two deletions where this was not possible (BgIII-NsiI, NsiI-NheI), advantage was taken of the fact that both of these constructions used restriction enzymes resulting in one $5^{\prime}$ - and one $3^{\prime}$-sticky end. A single-stranded DNA adaptor was therefore synthesized for the BglII-NsiI $15^{\prime}$ dGATCATGCA) or NsiI-Nhel (5'-dCTAGCTGCA) deletion that was complementary to both overhangs, and included an additional nucleotide necessary to give the correct reading frame and regenerate one of the original restriction sites (Table 1). The appropriate 5 -phosphorylated adaptor was added to the purified large BgIII-NsiI or NsiI-NheI resistant fragment, ligated using T4 DNA ligase, and transformed into Escherichia coli strain $\mathrm{DH} 5 \alpha \mathrm{F}^{\prime}$. Resulting transformants were screened with diagnostic restriction endonucleases, and the sequences of positive clones were confirmed by the dideoxy chain-termination method (Chen and Seeburg 1985). The double deletion d $425-464+499-558$ was made by ligating a BstXI-BglII fragment that contained the d425-464 deletion to an NsiI-BstXI fragment in the presence of the BglII-NsiI adaptor. The resulting double deletion within the carboxyl terminus was transferred into the GAL4-CC expression plasmid on an XmaI$B a m H I$ fragment, and protein of the expected molecular size was detected upon transfection and immunoblotting as described. Deletions are named according to the chicken c-Myb amino acids removed in each case (Table 1).

Plasmids encoding the GAL4(DBD) and LexA were kind gifts from Stan Fields and Katherine Martin, respectively. Expression of these proteins and their fusions was controlled by the SV40 promoter and polyA/splice site in the plasmid pECE (Ellis et al. 1986). Fusions of chicken c-Myb with either GAL4 or LexA were made by ligating the blunt SmaI site at c-Myb amino acid 233 to the upstream SmaI in pSG424 (Sadowski and Ptashne 1989 ) or the filled EcoRI of pBXLl (Martin et al. 1990). The GAL4-CC fusion protein includes c-Myb amino acids 233-641, whereas LexA-CC encodes c-Myb amino acids 234-641. Carboxy-terminally truncated versions of both fusions /GAL4-Cd and LexA-Cd) were created by cleavage at the MscI site in c-Myb (amino acid 427) and an XbaI site in the distal untranslated region, filling-in with Klenow, and religating (Table 1). Reporter plasmids bearing nine Myb-, five GAL4-, or six LexAbinding sites were derived from Elb-CAT, which contains a 
synthetic adenovirus Elb TATA sequence driving CAT gene expression (Lillie and Green 1989; Martin et al. 1990).

Deletions v-Myb-dH and VVP-dTA were made by ligating filled BstEII-XmaI and SmaI-HincII ends to give in-frame deletions of v-Myb amino acids 134-167 and 169-239, respectively. These mutant proteins migrated with the expected mobility on SDS-PAGE relative to their respective parent proteins. Numbering of $\mathrm{v}-\mathrm{Myb}$ residues begins with the initiating methionine encoded by the fused retroviral gag sequence at number one (Lane et al. 1990).

\section{Cells and media}

Quail QT6 fibroblasts were grown in Dulbecco's modified essential medium supplemented with $5 \%$ fetal calf serum, 4.5 grams/liter of glucose, nonessential amino acids, L-glutamine, sodium pynuvate, $100 \mu \mathrm{g} / \mathrm{ml}$ of streptomycin, and $100 \mathrm{U} / \mathrm{ml}$ of penicillin in a humidified $10 \% \mathrm{CO}_{2} / 90 \%$ air incubator at $37^{\circ} \mathrm{C}$. Chicken HD-11 macrophage and BK3A lymphocyte cells were grown in the same media with the addition of $5 \%$ heat-inactivated $\left(1 \mathrm{hr}\right.$ at $\left.56^{\circ} \mathrm{C}\right)$ chicken serum.

\section{DNA transfections, immunoblotting, and assays for CAT activity}

Transient transfections into QT6 quail fibroblasts and HD-11 macrophages were performed using a modification of the calcium phosphate procedure of Chen and Okayama (1987) as described previously (Ibanez and Lipsick 1990). Introduction of DNAs into BK3A B-cells was done using the DEAE-dextran method (Choi and Engel 1988). Transfections included 3-5 $\mu \mathrm{g}$ of activator plasmids that express proteins without the VP16 activation domain ( $\mathrm{v}-\mathrm{Myb}, \mathrm{CCC}$, dCd, GAL4-CC, etc.), from 0.1 to $0.5 \mu \mathrm{g}$ of the activators encoding VP1 6 fusion proteins (VVP, VVP-dTA), and 3-6 $\mu \mathrm{g}$ of inhibitor plasmid when present. Activator plasmids were cotransfected with CAT reporter DNA (1 $\mu \mathrm{g})$, tRNA $(3.8 \mu \mathrm{g})$, and $0.5 \mu \mathrm{g}$ of a plasmid expressing $\beta$-galactosidase ( $\beta$-gal) from the cytomegalovirus (CMV) promoter as an internal control for transfection efficiency. All experiments were performed at least twice, and representative results are shown. Specific details are given in the legend of each figure.

Half of the cells from each transfection plate were solubilized by boiling for $4 \mathrm{~min}$ in SDS-PAGE loading dyes. Normalized volumes of each were then subjected to SDS-PAGE through $10 \%$ gels, and the proteins were transferred to nitrocellulose (BA85; Schleicher \& Schuell, Keene, NH). Transiently expressed Myb proteins were detected using monoclonal antiMyb-2.2 and -2.7 antibodies (Evan et al. 1984). Blots were developed using rabbit anti-mouse $\mathrm{IgG}$ conjugated to alkaline phosphatase (Promega, Madison, WI) and BCIP/NBT /GIBCO BRL, Gaithersburg, MD|. The phase extraction method was employed to determine the CAT activity in normalized volumes of extract as described previously (Seed and Sheen 1988). Appropriate dilutions were assayed in those cases where the level of CAT activity indicated that substrate was limiting. A background value, generally $100-300 \mathrm{cpm}$, was obtained by extracting CAT assay mix to which no cell extract had been added. Activities shown in the figures have been corrected for background.

\section{Acknowledgments}

We thank Stan Fields, Paul Godowski, Katherine Martin, and Michael Green for kindly providing reagents used in these studies; Peter Kissel for oligonucleotide synthesis; Stan Fields and
Pat Hearing for critical reviews of the manuscript; and Judy Nimmo for excellent secretarial assistance. This work was supported in part by a U.S. Public Health Service grants (PO1 CA28146, 5T32CA09176, and K04CA01457). J.S.L. is a scholar of the Leukemia Society of America.

The publication costs of this article were defrayed in part by payment of page charges. This article must therefore be hereby marked "advertisement" in accordance with 18 USC section 1734 solely to indicate this fact.

\section{References}

Biedenkapp, H., U. Borgmeyer, A.E. Sippel, and K.-H. Klempnauer. 1988. Viral myb oncogene encodes a sequence-specific DNA binding activity. Nature 335: 835-837.

Boyle, W.J., J.S. Lipsick, and M.A. Baluda. 1986. Antibodies to the evolutionarily conserved aminoterminal region of the $\mathrm{v}-m y b$-encoded protein detect the c-myb protein in widely divergent metazoan species. Proc. Natl. Acad. Sci. 83: 46854689.

Chen, C.H. and Okayama. 1987. High-efficiency transformation of mammalian cells by plasmid DNA. Mol. Cell. Biol. 7: 2745-2752.

Chen, E.Y. and P.H. Seeburg. 1985. Supercoil sequencing: A fast and simple method for sequencing plasmid DNA. DNA 4: 165-168.

Choi, O.-R.B. and J.D. Engel. 1988. Developmental regulation of beta-globin gene switching. Cell 55: 17-26.

Ellis, L., E. Clauser, D.O. Morgan, M. Edery, R.A. Roth, and W.J. Rutter. 1986. Replacement of insulin receptor tyrosine residues 1162 and 1163 compromises insulin-stimulated kinase activity and uptake of 2-deoxyglucose. Cell 45: 721-732.

Evan, G.I., G.K. Lewis, and I.M. Bishop. 1984. Isolation of monoclonal antibodies specific for the products of the avian oncogene myb. Mol. Cell. Biol. 4: 2843-2850.

Evans, R.M. 1988. The steroid and thyroid hormone receptor superfamily. Science 240: 889-895.

Garcia, A., K. LaMontagne, D. Reavis, U. Stober-Grasser, and J.S. Lipsick. 1991. Determinants of sequence-specific DNAbinding by $\mathrm{p} 48^{\mathrm{v}-m y b}$. Oncogene 6: 265-273.

Gerondakis, S. and J.M. Bishop. 1986. Structure of the protein encoded by the chicken proto-oncogene c-myb. Mol. Cell. Biol. 6: 3677-3684.

Gewirtz, A.M. and B. Calabretta. 1988. A c-myb antisense oligodeoxynucleotide inhibits normal human hematopoiesis in vitro. Science 242: 1303-1306.

Godowski, P.J., D. Picard, and K.R. Yamamoto. 1988. Signal transduction and transcriptional regulation by glucocorticoid receptor-LexA fusion proteins. Science 241: 812-816.

Goff, S.A., K.C. Cone, and M.E. Fromm. 1991. Identification of functional domains in the maize transcriptional activator $\mathrm{Cl}$ : Comparison of wild-type and dominant inhibitor proteins. Genes \& Dev. 5: 298-309.

Gonda, T.J., N.M. Gough, A.R. Dunn, and J. de Blaquiere. 1985. Nucleotide sequence of cDNA clones of the murine myb proto-oncogene. EMBO /. 4: 2003-2008.

Grasser, F.A., T. Graf, and J.S. Lipsick. 1991. Protein truncation is required for the activation of the c-myb proto-oncogene. Mol. Cell. Biol. 11: 3987-3996.

Grasser, F.A., K. LaMontagne, L. Whittaker, S. Stohr, and J.S. Lipsick. 1992. A highly conserved cysteine in the v-Myb DNA-binding domain is essential for transformation and transcriptional trans-activation. Oncogene 7: 1005-1009.

Howe, K.M., C.F.L. Reakes, and R.J. Watson. 1990. Characterization of the sequence-specific interaction of mouse c-myb 
protein with DNA. EMBO I. 9: 161-169.

Hu, Y.L., R.G. Ramsay, C. Kanei-Ishii, S. Ishii, and T.J. Gonda. 1991. Transformation by carboxyl-deleted Myb reflects increased transactivating capacity and disruption of a negative regulatory domain. Oncogene 6: 1549-1553.

Ibanez, C.E. and J.S. Lipsick. 1988. Structural and functional domains of the myb oncogene: Requirements for nuclear transport, myeloid transformation, and colony formation. $I$. Virol. 62: 1981-1988.

. 1990. trans activation of gene expression by v-myb. Mol. Cell. Biol. 10: 2285-2293.

Introna, M., J. Golay, J. Frampton, T. Nakano, S.A. Ness, and T. Graf. 1990. Mutations in v-myb alter the differentiation of myelomonocytic cells transformed by the oncogene. Cell 63: 1289-1297.

Kakidani, H. and M. Ptashne. 1988. GAL4 activates gene expression in mammalian cells. Cell 52: 161-167.

Kalkbrenner, F., S. Guehmann, and K. Moelling. 1990. Transcriptional activation by human c-myb and v-myb genes. Oncogene 5: 657-661.

Kanei-Ishii, C., E.M. MacMillan, T. Nomura, A. Sarai, R.G. Ramsay, S. Aimoto, S. Ishii, and T.J. Gonda. 1992. Transactivation and transformation by $\mathrm{Myb}$ are negatively regulated by a leucine-zipper structure. Proc. Natl. Acad. Sci. 89: 3088-3092.

Klempnauer, K.-H., G. Ramsay, J.M. Bishop, M.G. Moscovici, C. Moscovici, J.P. McGrath, and A.D. Levinson. 1983. The product of the retroviral transforming gene v-myb is a truncated version of the protein encoded by the cellular oncogene c-myb. Cell 33: 345-355.

Klempnauer, K.-H., H. Arnold, and H. Biedenkapp. 1989. Activation of transcription by v-my $b$ : Evidence for two different mechanisms. Genes \& Dev. 3: 1582-1589.

Lane, T.N., C.E. Ibanez, A. Garcia, T. Graf, and J.S. Lipsick. 1990. Transformation by $\mathrm{v}-m y b$ correlates with transactivation of gene expression. Mol. Cell. Biol. 10: 2591-2598.

Lillie, J.W. and M.R. Green. 1989. Transcription activation by the adenovirus Ela protein. Nature 338: $39-44$.

Lipsick, J.S. 1987. v-myb does not prevent the expression of c-myb in avian erythroblasts. J. Virol. 61: 3284-3287.

Lüscher, B. and R.N. Eisenman. 1990. New light on Myc and Myb. Part II. Myb. Genes \& Dev. 4: 2235-2241.

Lüscher, B., E. Christenson, D.W. Litchfield, E.G. Krebs, and R.N. Eisenman. 1990. Myb DNA binding inhibited by phosphorylation at a site deleted during oncogenic activation. Nature 344: 517-522.

Maniatis, T., E.F. Fritsch, and J. Sambrook. 1982. Molecular cloning: A laboratory manual. Cold Spring Harbor Laboratory, Cold Spring Harbor, New York.

Martin, K.J., J.W. Lillie, and M.R. Green. 1990. Evidence for interaction of different eukaryotic transcriptional activators with distinct cellular targets. Nature 346: 147-152.

Mucenski, M.L., K. McLain, A.B. Kier, S.H. Swerdlow, C.M Schreiner, T.A. Miller, D.W. Pietryga, W.J. Scott Jr. and S.S. Potter. 1991. A functional c-myb gene is required for normal murine fetal hepatic hematopoiesis. Cell 65: 677-689.

Ness, S.A., A. Marknell, and T. Graf. 1989. The v-myb oncogene product binds to and activates the promyelocyte-specific mim-1 gene. Cell 59: 1115-1125.

Nomura, N., M. Takahashi, M. Matsui, S. Ishii, T. Date, S. Sasamoto, and R. Ishizaki. 1988. Isolation of human cDNA clones of myb-related genes, A-myb and B-myb. Nucleic Acids Res. 16: 11075-11089.

Oehler, T., H. Arnold, H. Biedenkapp, and K.-H. Klempnauer. 1990. Characterization of the $\mathrm{v}-m y b$ DNA binding domain. Nucleic Acids Res. 18: 1703-1710.
Pugh, B.F. and R. Tjian. 1990. Mechanism of transcriptional activation by Spl: Evidence for coactivators. Cell 61: 11871197.

Ramsay, R.G., S. Ishii, Y. Nishina, G. Soe, and T.J. Gonda. 1989. Characterization of alternate and truncated forms of murine c-myb proteins. Oncogene Res. 4: 259-269.

Ramsay, R.G., S. Ishii, and T.J. Gonda. 1991. Increase in specific DNA binding by carboxyl truncation suggests a mechanism for activation of Myb. Oncogene 6: 1875-1879.

1992. Interaction of the Myb protein with specific DNA binding sites. J. Biol. Chem. 267: 5656-5662.

Rosson, D. and E.P. Reddy. 1986. Nucleotide sequence of chicken c-myb complementary DNA and implications for myb oncogene activation. Nature 319: 604-606.

Sadowski, I. and M. Ptashne. 1989. A vector for expressing GAL4(1-147) fusions in mammalian cells. Nucleic Acids Res. 17: 7539 .

Sakura, H., C. Kanei-Ishii, T. Nagase, H. Nakagoshi, T.J. Gonda, and S. Ishii. 1989. Delineation of three functional domains of the transcriptional activator encoded by the c-myb protooncogene. Proc. Natl. Acad. Sci. 86: 5758-5762.

Schuler, G.D., S.F. Altschul, and D.J. Lipman. 1991. A workbench for multiple alignment construction and analysis. Proteins Struct. Funct. Genet. 9: 180-190.

Seed, B. and J.-Y. Sheen. 1988. A simple phase-extraction assay for chloramphenicol acyltransferase activity. Gene 67: 271277.

Shen-Ong, G.L.C. 1990. The myb oncogene. Biochim. Biophys. Acta 1032: 39-52.

Stober-Grasser, U. and J.S. Lipsick. 1988. Specific amino acid substitutions are not required for transformation by $\mathrm{v}-m y b$ of avian myeloblastosis virus. J. Virol. 62: 1093-1096.

Stober-Grasser, U., B. Brydolf, X. Bin, F.A. Grasser, R.A. Firtel, and J.S. Lipsick. 1992. The Myb DNA-binding domain is highly conserved in Dictyostelium discoideum. Oncogene 7: 589-596.

Tice-Baldwin, K., G.R. Fink, and K.T. Arndt. 1989. BAS1 has a myb motif and activates HIS4 transcription only in combination with BAS2. Science 246: 931-935.

Triezenberg, S.J., R.C. Kingsbury, and S.L. McKnight. 1988. Functional dissection of VP16, the transactivator of herpes simplex virus immediate early gene expression. Genes \& Dev. 2: 718-729.

Weston, K. and J.M. Bishop. 1989. Transcriptional activation by the v-myb oncogene and its cellular progenitor, c-myb. Cell 58: 85-93. 


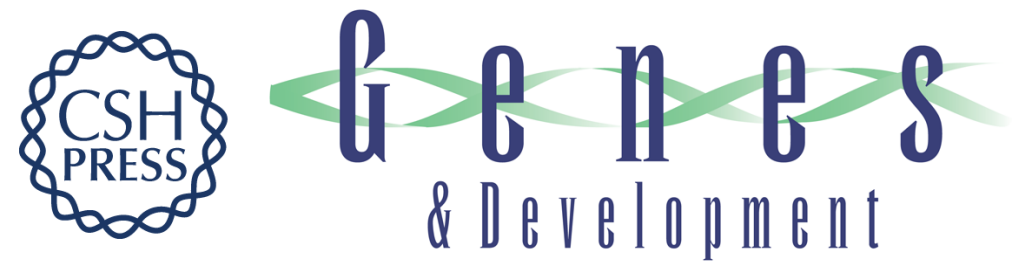

\section{Carboxy-terminal elements of c-Myb negatively regulate transcriptional activation in cis and in trans.}

J W Dubendorff, L J Whittaker, J T Eltman, et al.

Genes Dev. 1992, 6:

Access the most recent version at doi:10.1101/gad.6.12b.2524

References This article cites 51 articles, 21 of which can be accessed free at:

http://genesdev.cshlp.org/content/6/12b/2524.full.html\#ref-list-1

License

Email Alerting

Service

Receive free email alerts when new articles cite this article - sign up in the box at the top right corner of the article or click here.

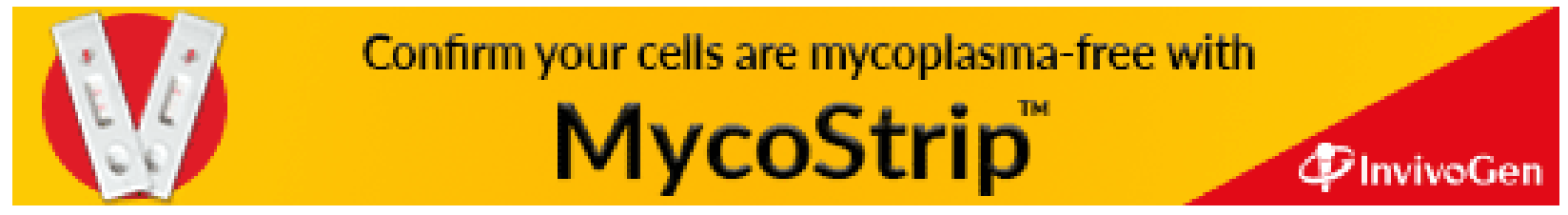

